Original Research Paper

\title{
Intravenous Injection of Umbilical Cord-Derived Mesenchymal Stem Cells Improved Regeneration of Rat Liver after $2 \mathrm{AAF} / \mathrm{CCl}_{4}$-Induced Injury
}

\author{
1,2,3,4,* Isabella Kurnia Liem, ${ }^{5,6}$ Reni Oktavina, ${ }^{5,7}$ Zakiyah, ${ }^{1,3}$ Dian Anggraini, \\ ${ }^{1}$ Irwina Eka Deraya, ${ }^{8}$ Ria Kodariah, ${ }^{8}$ Ening Krisnuhoni and ${ }^{8,9}$ Puspita Eka Wuyung \\ ${ }^{I}$ Department of Anatomy, Faculty of Medicine, Universitas Indonesia, Jakarta, Indonesia \\ ${ }^{2}$ Stem Cell Medical Technology Integrated Service Unit, Cipto Mangunkusumo Central Hospital, \\ Faculty of Medicine, Universitas Indonesia, Jakarta, Indonesia \\ ${ }^{3}$ Stem Cell and Tissue Engineering Cluster, Indonesian Medical Education and Research Institute, \\ Faculty of Medicine, Universitas Indonesia, Jakarta, Indonesia \\ ${ }^{4}$ Integrated Laboratory, Faculty of Medicine, Universitas Indonesia, Jakarta, Indonesia \\ ${ }^{5}$ Master Program of Biomedical Sciences, Faculty of Medicine, Universitas Indonesia, Jakarta, Indonesia \\ ${ }^{6}$ Department of Anatomy, Faculty of Medicine and Health Science, Universitas Kristen Krida Wacana, Jakarta, Indonesia \\ ${ }^{7}$ Department of Anatomy, Faculty of Medicine, Universitas Yarsi, Jakarta, Indonesia \\ ${ }^{8}$ Department of Anatomical Pathology, Faculty of Medicine, Universitas Indonesia, Jakarta, Indonesia \\ ${ }^{9}$ Animal Research Facilities, Indonesian Medical Education and Research Institute, \\ Faculty of Medicine, Universitas Indonesia, Jakarta, Indonesia
}

Article history

Received: 28-01-2021

Revised: 22-04-2021

Accepted: 03-05-2021

Corresponding Author: Isabella Kurnia Liem Department of Anatomy, Faculty of Medicine, Universitas Indonesia, Jakarta, Indonesia

Email: bellajo04@gmail.com
Abstract: The effectivity of Mesenchymal Stem Cell (MSC) therapy for chronic liver injury is still questioned due to its possibility to have a pro-fibrotic effects. Other consideration is the preferably peripheral Intravenous (IV) route of application rather than direct to the target organ, such as portal vein or splenic vein, since the most of MSC will be trapped in the lung and other organs. Therefore, a study has been carried out in an animal model of chronic liver injury, $2 \mathrm{AAF} / \mathrm{CCl}_{4}$ rats, to find out whether IV injection of single dose, $1 \times 10^{6}$ human umbilical cord-derived MSC (hUC-MSC) can regenerate the liver tissue and reduce the fibrosis. Male Wistar rats $(\mathrm{n}=$ 18,8 weeks, $160-200 \mathrm{~g}$ ) were divided into three groups of six rats, i.e., group I (control/healthy rats), group II ( $2 \mathrm{AAF} / \mathrm{CCl}_{4}$-induced liver injury with hUC-MSC injected rats) and group III (2AAF/CCl 4 -incuded liver injury without hUC-MSC injected rats). Gross anatomical features of the livers and blood examination were tested. There was no significant different of the Alanine Aminotransferase (ALT) and Albumin serum level between groups; however there was a tendency of ALT decrease and Albumin increase in stem cells treated rats (group II). Histopathological observation using hematoxylin eosin and Masson's trichrome staining showed an improvement in the liver damage condition (reduction of necrosis and coverage area of fat degeneration) and an improvement in the fibrosis condition in the group II compared to the group III. None of group II rat had fallen into cirrhosis as seen in group III. Immunohistochemistry staining against Caspase 3 (biomarker for apoptosis) also showed significant reduction ( $\mathrm{p}=0.038$; Tukey multiple comparison test) of group II expression index (2.74\%) compared to the group III $(8.64 \%)$. In conclusion, IV injection of single dose, $1 \times 10^{6}$ hUC-MSC could regenerate the liver tissue and reduce the fibrosis in $2 \mathrm{AAF} / \mathrm{CCl}_{4}$ rats model of chronic liver injury.

Keywords: $2 \mathrm{AAF} / \mathrm{CCl}_{4}$, Liver Fibrosis, Liver Injury, Liver Regeneration, MSC, Caspase 3 


\section{Introduction}

Liver injury is still a neglected global health problem in its early stages and has a high potential to progress to liver fibrosis (scar tissue formation), ending in cirrhosis that leads to death (Marcellin and Kutala, 2018). Although the morbidity and mortality is increasing year to year, until now no effective therapy has been found. Globally, total cases of cirrhosis reached 41.4 million people in 2017, with the number of deaths reaching more than 1.32 million people or $2.4 \%$ of the world's population (GBD 2017 Cirrhosis Collaborators, 2020). Cirrhosis conditions cannot be cured with conventional medicine. The most widely used treatment method for chronic liver damage to restore liver mass is a liver transplant; however, there are some shortages, such as limitation of the availability of the liver organ and immunological rejection. Therefore, nowadays, there is a consideration for using cell therapy. One of the candidate is stem cells therapy as an adjuvant to promote liver regeneration (Nicolas et al., 2016; Yun et al., 2016).

In chronic liver injury, hepatocytes are no longer able to regenerate the liver (decrease of their proliferation capacity). It is featured with the accumulation of collagen in Extracellular Matrix (ECM). This condition occurs in alcoholic and non-alcoholic cirrhosis, chronic viral hepatitis and primary biliary cirrhosis. If this condition proceed, although there are activation of liver progenitor cells population, recovery of epithelial cell mass, architecture and liver function will be exceeded by collagen deposition that lead the liver falls into the final state, liver cirrhosis (Riehle et al., 2011). In chronic liver injury, cytokine production by damaged parenchymal cells and disruption of ECM are stimuli for HSC (Lo and Kim, 2017). Responding to this stimuli, Hepatic Stellate Cells (HSC) are activated and their phenotypes turn into fibrogenic myofibroblast (Xu et al., 2014) and take part in the regulation of various forms of liver inflammation such as increase the expression of inflammatory receptors, including chemokine receptors, inflammatory mediators in the form of chemokines andleukocyte chemoactivity. This initiation phase changes the expression of the genes and phenotypes of liver cells; thereby, it makes them more responsive and perpetuates HSC activation to generate collagen accumulation in ECM and progressive fibrosis (Tsuchida and Friedman, 2017).

Recently, cell therapy has become an alternative treatment for chronic liver injury. It is developed to prevent worsening of the disease, support the liver regeneration and hopefully can reduce the mortality rate. Utilization of therapeutic cells can be carried out through stem cells that have the ability to modulate the endogenous regeneration process of the liver and inhibit fibrosis (Nicolas et al., 2016; Yun et al., 2016). There are several sources of stem cells to treat liver disease, especially in cirrhosis, including fetal hepatic stem cells or hepatoblasts (Habeeb et al., 2015), fetal biliary tree stem cells (Cardinale et al., 2014), Hepatic Progenitor
Cells (HPC) (Best et al., 2015) and Induced Pluripotent Stem Cells (IPSC) (Zhu et al., 2014). Nowadays, Mesenchymal Stem Cells (MSC) are known and have been studied as the most promising and potential therapy for liver cirrhosis (Eom et al., 2015; Cao et al., 2020). MSC can originate from various tissues, one of them is the umbilical cord that has several benefits. Umbilical cord is known as a birth waste and a rich source of stem cells after bone marrow (Fazzina et al., 2015; Vangsness $\mathrm{Jr}$ et al., 2015). MSC isolated from the umbilical cord have the ability to secrete tropic factors such as cytokines, chemokines and growth factors to encourage the liver regeneration through reducing inflammation or fibrosis, immunomodulatory effects, also tissue repair (Troyer and Weiss, 2008; Ishige et al., 2009; Eom et al., 2015). It is also suggested that MSC have a capacity for multilineage differentiation, including differentiation into hepatocytes (Vangsness Jr et al., 2015; Haldar et al., 2016).

Although MSC application for liver fibrosis has became the attention of clinicians and scientists, the mode of action is still unclear. MSC may have direct antifibrotic effects; however, its possibility to have a profibrotic effects should be concerned as well (Haldar et al., 2016). Several basic and clinical studies on the administration of MSC for liver fibrosis showed positive improvement of liver functions (increase serum albumin level), hepatocyte integrity (decrease serum level of Alanine Transaminase/ALT and Aspartate Transaminase/AST) improvement of tissue morphology, decrease of fibrosis and decrease of hepatocyte apoptosis (Hwang et al., 2012; Volarevic et al., 2014; Haldar et al., 2016). For example, in a study done by Motawi et al. (2014) MSC administration in carbon tetrachloride $\left(\mathrm{CCl}_{4}\right)$ inducedliver fibrosis rats could repair the fibrotic tissue better than simvastatin as seen on the improvement of serum liver function tests. MSC also decreased fibrosis score support by improvement of molecular finding, i.e., increased of Matrix Metalloproteinase-1 (MMP-1) gene expression, decreased liver procollagens I and III, Tissue Inhibitor of Metalloproteinase-1 (TIMP-1) and endoglin gene expressions, as well as decreased of Transforming Growth Factor-beta (TGF-ß1) immunostaining (Motawi et al., 2014). Nevertheless, a negative result, i.e., MSC did not reduce fibrosis, was ever been reported (Carvalho et al., 2008).

Dose, timing and route of the administration of MSC are important for therapeutic effect (Haldar et al., 2016; Cao et al., 2020). Administration doses in clinical studies were reported $0.5 \times 10^{6}$ cells $/ \mathrm{kg}$ body weight (bw) for allogeneic infusion and $1 \times 10^{6}$ cells $/ \mathrm{kgbw}$ to $3.4 \times 10^{8}$ cells/kgbw for autologous infusion. In animal studies using rat or mouse, the dose was ranged from $0.25 \times 10^{6}$ cells to $1.6 \times 10^{7}$ cells, with the most widely used dosage was $1 \times 10^{6}$ cells (Haldar et al., 2016). Although it is not possible to determine the optimal dose of MSC to achieve 
therapeutic response, there was a trend of dose dependent reduction of fibrosis. The timing of administration, whether it is single dose or splitting dose, has not been proven yet which one is better (Haldar et al., 2016). In seriously ill patients, preferred route of administration is peripheral intravenous rather than direct to the target organ, such as portal vein or splenic vein, because it is safer, more comfortable and allows to repeat and to infuse large amount of administrations (Eggenhofer et al., 2012). In the intravenous route, most of the MSC will be trapped in the lung and the rest in the spleen, liver, bone marrow, thymus, kidney, skin and tumors (if any), which probably due to the bigger size of MSC $( \pm 20-30 \mu \mathrm{m})$ compare to the capillaries $(<20 \mu \mathrm{m})$ and their strong adhesion properties of MSC (Crop et al., 2011; Shi et al., 2011). In vivo tracing of MSC showed that only a small number of these cells will home in the target organ and stay not detected 7-14 days after infusion. This suggests that MSC can produce clinical effects through paracrine signaling, such as Hepatocyte Growth Factor (HGF), Vascular Endothelial Growth Factor (VEGF), Prostaglandin E2 (PGE2) and Indoleamine 2,3-Dioxygenase (IDO) rather than transdifferentiation (Cao et al., 2020).

Several studies on human clinical trials and animal studies have provided new hope for the treatment of liver fibrosis. However, most of the study was exploring the potency of BM-MSC and did not explored enough the umbilical cord-derived MSC (UC-MSC). There are also conflicting research results; whether MSC could repair liver damage and reduce fibrosis (antifibrosis) or conversely. Liver fibrosis or cirrhosis is a later stage of liver injury or post-injury with decreasing ability of hepatocyte proliferation. The patients usually fall into severe illness and have weak physical condition that making them suffer more to obtain bone marrow aspiration procedure for autologous therapy. In addition, given the ability of MSC to produce soluble/paracrine factors, it is possible to administrate it intravenously, which is less invasive (Haldar et al., 2016; Cao et al., 2020). Therefore, this study has been carried out in an animal model of chronic liver injury, 2Acetylaminofluorene ( $2 \mathrm{AAF}) / \mathrm{CCl}_{4}$ rats, to find out whether intravenous injection of single dose, $1 \times 10^{6}$ UC-MSC can regenerate the liver tissue and reduce the fibrosis.

\section{Materials and Methods}

\section{Animal Handling}

Male Wistar rats $(\mathrm{n}=18)$, aged 8 weeks with a body weight of $160-200 \mathrm{~g}$, were obtained from Animal Research Division of Research and Development Agency, Ministry of Health of the Republic Indonesia. Animals were housed in a constant temperature, under a $12 \mathrm{~h}$ dark/light cycle and supplied with laboratory chow and water ad libitum. All animal experiments were approved by Ethics Committee of Faculty of Medicine
Universitas Indonesia (No.1277/UN2.F1/ETIK/2018). Eighteen rats were divided into three groups of six rats. Group I was the control group (healthy rats). Group II was $2 \mathrm{AAF} / \mathrm{CCl}_{4}$ induced liver injury rats and treated with Human Umbilical Cord Mesenchymal Stem Cells (hUC-MSC). Group III was $2 \mathrm{AAF} / \mathrm{CCl}_{4}$-induced liver injury rats, but did not treat with hUC-MSCs. To determine the liver function, laboratory blood examination of serum ALT and Albumin were performed using the blood that was taken from orbital vein. All groups of rats were decapitated at two weeks after the induction and/or stem cells injection (week $\left.14^{\text {th }}\right)$, followed by collection of the liver.

\section{$2 \mathrm{AFF} / \mathrm{CCl}_{4}$ Induction and hUC-MSC Injection}

The 2-Acetylaminofluorene (2AAF; Sigma-Aldrich ${ }^{\circledR}$, Darmstadt, Germany) and carbon tetrachloride (CCL4; MERCK, Munchen, Germany) induction was done in 12 weeks. The stem cells injection was done one day after the last induction. Human Umbilical Cord blood-derived Mesenchymal Stem Cells (hUC-MSC; CD73 99.8\%, CD105 95\%, CD90 99.9\%, negative marker 0.4\%) for liver regeneration treatment was produced by Stem Cells and Tissue Engineering Cluster (SCTE), Indonesian Medical Education and Research Institute (IMERI), Faculty of Medicine Universitas Indonesia (FMUI). Group I (control group) received equal quantities of subcutaneous injection of olive oil and intragastric Polyethylene Glycol (PEG) for 12 weeks and received intravenous injection of 1000 $\mu \mathrm{L}$ physiological $\mathrm{NaCl}$ once, one day after. Group II (2-AAF/CCl ${ }_{4}$ group with stem cells) was induced with subcutaneous injection of $2 \mathrm{~mL} / \mathrm{kg} \mathrm{CCl}_{4}$ in olive oil twice a week for 12 week (week $1^{\text {th }}-8^{\text {th }} \mathrm{CCl}_{4}$ : olive oil $=1: 1$ and week $9^{\text {th }}-12^{\text {th }} \mathrm{CCl}_{4}$ : olive oil $=3: 7$ ) and intragastric 10 $\mathrm{mg} / \mathrm{kg}$ 2AAF in PEG everyday for two weeks (week $\left.9^{\text {th }}-12^{\text {th }}\right)$ and treated with intravenous injection of $1 \times 10^{6}$ hUC-MSC in $1000 \mu \mathrm{L}$ physiological $\mathrm{NaCl}$ once, one day after $2 \mathrm{AAF} / \mathrm{CCl}_{4}$ induction. Group III $\left(2 \mathrm{AAF} / \mathrm{CCl}_{4}\right.$ group without stem cells) was induced with $\mathrm{CCl}_{4}$ and $2 \mathrm{AAF}$ with the same regimen as group II and received intravenous injection of $1000 \mu \mathrm{L}$ physiological $\mathrm{NaCl}$. All groups were decapitated two week after the induction (week $14^{\text {th }}$ ).

\section{Histopathological Staining}

For histopathological analysis, liver specimens were fixed for 12-24 hours in 10\% neutral formalin solution, embedded in paraffin, sectioned as thick as $3 \mu \mathrm{m}$ and were stained with Hematoxylin Eosin (HE) to evaluate the liver morphology and pathological process, Masson's Trichrome (MT) to evaluate the degree of fibrosis, immunostaining against Caspase-3 (diluted 1:50, Abcam, ab13847) to observe the cells apoptosis. Histofine universal immuno-peroxidase polymer (NICHIREI, Tokyo, Japan) was used as secondary antibody and 3,3'-Diaminobenzidine Tetrahydrochloride 
(DAB) was used as a chromogen, yielding a brown signal. At the end of process, the tissue was cleared by immersing it in xylol solution, mounted in entelan and covered by a cover glass. Histopathological evaluation was performed under light microscope (LEICA type DM750, Wetzlar, Germany).

\section{Data collection and Analysis}

Morphology of the liver and Histopathology (HE and MT) were reported descriptively. Observation of the severity of liver damage in the HE staining's tissue was determined using French et al scores, includes fat degeneration, necrosis, cell swelling and inflammation, as follows: $0=$ no visible liver cell damage, $1=$ focal damage less than $25 \%$ of tissue, 2 = focal damage $25-50 \%$ of tissue, 3 = extensive but focal, $4=$ total damage/necrosis (Eidi et al., 2013). In the MT staining's tissue, the degree of fibrosis was observed and determined by Non-Alcoholic Fatty Liver Disease (NAFLD) scores (Onyekwere et al., 2015). For SPSS statistical consideration, the score was adjusted for the division of staging/fibrosis as follows: $0=$ no fibrosis, 1 = perisinusoidal fibrosis in zone 3 or portal or periportal, 2 = perisinusoidal fibrosis in zone 3 and fibrosis in portal/periportal, 3 = bridging fibrosis, $4=$ cirrhosis. In addition, in each slice, the percentages of damaged and fibrosed areas was assessed in five microscopic fields and then averaged.

Data of ALT, Albumin and Caspase-3 were tabulated, tested the normality using Shapiro Wilk normality test and analyzed the significant different between groups using one-way ANOVA analysis of variance. The criteria for statistical significance was $p<0.05$. All values were expressed as mean values $\pm \mathrm{SD}$. Observation of each antibody expression was carried out in five fields of liver tissue. Cell counts and measurements of the surface area of the liver tissue are performed using the ImageJ application. Statistical analysis was carried out using SPSS 20.0 for Windows statistical package.

\section{Results}

Macroscopic observation and laboratory blood examination showed the trend of descriptive changes between group II and III (Fig. 1). Group II had similar appearance compared to group I, i.e. the liver had smooth surface whereas, group III had uneven surface. Group III had the highest level of the ALT, followed by group II and group I. ALT levels in group II was 1.2 times lower than group III. Group III had the lowest Albumin level, followed by the group II and group I. Nevertheless, one way ANOVA test resulted that both ALT and Albumin levels in the three groups were not significantly different $(\mathrm{p}=0.302$ and $\mathrm{p}=0.103)$.

Observation of HE staining showed that group III (2$\mathrm{AAF} / \mathrm{CCl}_{4}$ group without hUC-MSC) had severe liver damage compared to the group II (2-AAF/CCl 4 group with hUC-MSC) (Fig. 2, and Tables 1 and 2). Group I, the healthy control group, showed classic lobular with hepatocytes arranged radially to the central vein, which is separated by sinusoid. Group II had liver damage, includes fat degeneration (score 0-1), cell swelling (score 1-4) and inflammation (0-1). Group III showed all criteria of liver damage, includes fat degeneration (score 0-1), necrosis (score 0-1), cell swelling (score 04) and inflammation (score 0-1). Group III showed extensive fat degeneration (67\%) than group II (30\%). In all observed area of group II, cell swelling could be seen, but not the necrosis. Both group II and III showed irregular liver's lobules.

The MT staining showed decrease of collagen distribution in group II compared to group III (Fig. 1 and Table 1 and 2). It could be seen that distribution of collagen fibers in zone 3 per sinusoidal or porta/ periportal in group II decreased. Moreover, there was no area of cirrhosis in group II compared to group III that showed one case of cirrhosis. In control group, the degree of fibrosis score was 0 , which indicated normal collagen fiber distribution. The degree of fibrosis ranged 0-2 in group II, however it ranged 1-4 in group III. The fibrosis could be seen in all observed area of group III, but it was decreased to $87 \%$ in group II.

The expression of Caspase 3 between group showed a significant difference ( $\mathrm{p}=0.004$; one way ANOVA; Fig. 3). The post hoc test, Tukey multiple comparison test, showed that group II significantly different with group III ( $\mathrm{p}$ $=0.038)$ and did not differ with group I $(p=0.432)$. Caspase 3 expression of group III was more than 3 times higher compared to group II (Fig. 3E). In group I, the expression index was zero (Fig. 3B).

\section{Discussion}

Chronic severe liver injury caused by various factors including alcohol consumption, viral infections (hepatitis $\mathrm{B}$ and $\mathrm{C}$ ), NAFLD and non-alcoholic steatohepatitis (NASH) (Zhou et al., 2014; Marcellin and Kutala, 2018) that has becoming a global health problem had challenged us to develop an animal model of it to understand the disease progression, regeneration and management. In this study, we used $2 \mathrm{AAF} / \mathrm{CCL}_{4}$ in rat that cause liver damage mimicked human severe liver injury, i.e., extensive liver damage and suppression of hepatocyte proliferation. $\mathrm{CCL}_{4}$ can trigger necrosis in lobular zones of the liver leading to acute inflammation (Mao et al., 2014) due to its active metabolite, the free radicals of Trichloromethyl $\left(\mathrm{CCl}_{3}{ }^{+}\right)$(Omara et al., 2018). Meanwhile, 2AAF is known to trigger liver injury by changing the detoxification enzyme level (imbalanced antioxidant status), inflammation and apoptosis (Hasan and Sultana, 2015) that leads to the hepatocyte 
proliferation blocking (Abdellatif et al., 2017). This combination model has been used previously by Abdellatif et al (2017) to study the response of oval cells after human umbilical cord blood stem cells (mononuclear cells) transplantation. Our study demonstrated that the induction caused a liver tissue damage, includes the fat degeneration, cell swelling, necrosis and inflammation (Fig. 2E, Tables 1 and 2) and generation of extensive fibrosis to cirrhosis (shown by collagen deposition in MT staining; Fig. 2F, Tables 1 and 2). This model also shown a tendency of ALT increase and Albumin decrease (Fig. 1 ), which indicating a damage of liver parenchymal cells (Abdellatif et al., 2017).

The liver damage in this model is also supported by the increased of Caspase 3 expression that implied the increased of apoptosis of the liver cells (Hasan and Sultana, 2015). In the group III, Caspase 3 was expressed more than eight times compared to the control group (Fig. 3). Apoptosis in our model was one of the sign of liver injury that could be cause by both of $2 \mathrm{AAF}$ and $\mathrm{CCl}_{4}$. The mechanism of apoptosis was different but both caused oxidative stress due to the production of substantial Reactive Oxygen Species (ROS), which leads to the mitochondria damage (Lin et al., 2019). The chemical exposure might have an effect on DNA damage through the formation of free radicals. The DNA damage activates cytoplasmic sensors and results in decreased production of anti-apoptotic protein (Bcl-2) and an increase in the amount of pro-apoptotic protein (Bax/Bak). Consequently, leakage of cytochrome c protein that is usually produced in mitochondria. Cytochrome c protein leakage can activate various caspase series, starting with initiation by Caspase- 9 and then is executed by Caspase 3 (Elmore, 2007; Lin et al., 2019).

Our study in injecting single dose, $1 \times 10^{6}$ hUC MSC intravenously into the model of severe chronic liver injury, $2 \mathrm{AAF} / \mathrm{CCl} 4$ rat, has shown a positive result in supporting the liver regeneration. The group II (2AAF/CCl4 with hUC-MSC) showed an improvement in the liver condition. The liver damage has decreased compared to the group III (2-AAF/CCl4 without hUCMSC), especially in the degree of necrosis and coverage area of fat degeneration, even though the degree of inflammation and cell swelling has not changed. The fibrosis of the liver also improved, shown by decreased of the fibrosis level and coverage area. None of group II rat had fallen into cirrhosis as seen in group III. In line with our study, (Burra et al., 2012) reported that intravenous administration of hUC-MSC on $\mathrm{CCL}_{4}$-induced mice experienced liver recovery, i.e., decrease inflammatory cells and necrosis area and increase albumin synthesis. Moreover, some clinical trials in primary biliary cirrhosis, acute in chronic liver failure, decompensated liver cirrhosis and liver cirrhosis caused by autoimmune disease (as reviewed by Yang et al., 2020) have shown improvement of liver function. Although statistically insignificant, in this study, the liver tissue improvement appeared to be accompanied by a trend towards decrease in ALT and increase in albumin (Fig. 1D and 1E), which implied a trend of increase in liver function. ALT and Albumin are common parameters used as indicator for hepatocyte damage. In liver disease, level of serum ALT increase and level of serum of albumin decrease (Giannini et al., 2005; Maulidia et al., 2020). In acute condition, the serum ALT usually increase significantly; however, in chronic condition or liver cirrhosis, the level depends on the stage of the disease. In compensated phase, it can stay in normal range or fluctuating around the upper reference value; however in the decompensated phase the level tend to increase (Giannini et al., 2005; Maulidia et al., 2020). In the alteration of Aminotransferase levels (ALT and/or Aspartate aminotransferase/AST), the changes of albumin level in the blood is prognostic for liver function since albumin is produced by hepatocytes (Maulidia et al., 2020).

Although it has been shown that hUC-MSC could support liver regeneration, the repair mechanism has not fully been understood (Haldar et al., 2016; Cao et al., 2020). Immunohistochemical analysis for the apoptosis indicated by Caspase-3 expression has shown that hUCMSC treatment could significantly decrease the Caspase 3 expression (Fig. 3) compare to untreated group. Supporting our research, Caspase 3 inactivation on NAFLD model mice (Methionine-and CholineDeficient/MCD) by Thapaliya et al (2014) has shown that inactivation of Caspase 3 was associated with reduction hepatic collagen deposition. This was known to be associated with the reduced levels of apoptosis and expression of cytokines involved in inflammatory signaling. This implied that the administration hUCMSC could inhibit apoptosis and stimulate regeneration (Meier et al., 2013; $\mathrm{Hu}$ and $\mathrm{Li}, 2019$ ). Some evidences have indicated that MSC inhibits the progression of fibrosis due to its immune-modulatory properties (Cao et al., 2020). The immune cell function is modulated by MSC to create a hepatoprotective environment through the paracrine effects (PDE2, VEGF, HGF, IDO, TGF- $\beta$, IL-10, etc.) and/or direct cell to cell interaction (Jiang and $\mathrm{Xu}, 2019$; Tsuchiya et al., 2019; Cao et al., 2020; Yang et al., 2020). Together with the histopathology finding and liver function test, this proved that hUC-MSC play a role in reducing hepatic cells apoptosis, reducing fibrosis and promoting liver tissue repair. 

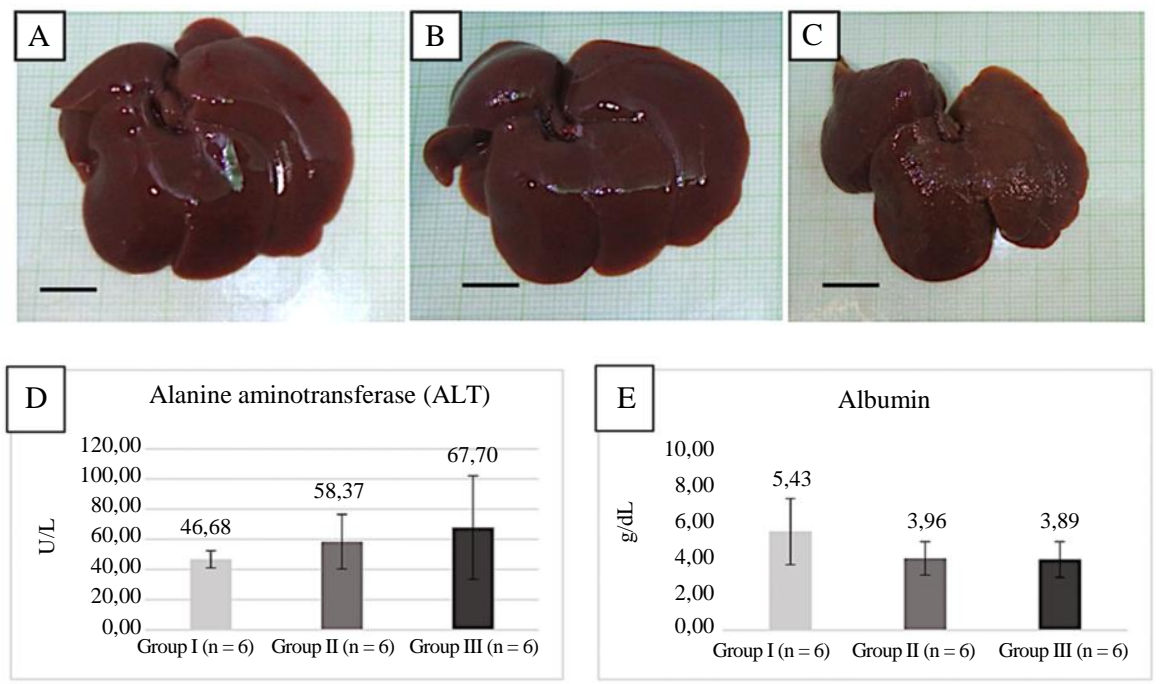

Fig. 1: Gross anatomical features of the livers and laboratory blood examination results. A. Group I (Control). B. Group II (2AAF/CCl4 with hUC-MSC). C. Group III (2-AAF/ CCl4 without hUC-MSC). The livers were laid down on the milimeter paper, in the same magnification. scale bar $=10 \mathrm{~mm}$. D. ALT and E. Albumin
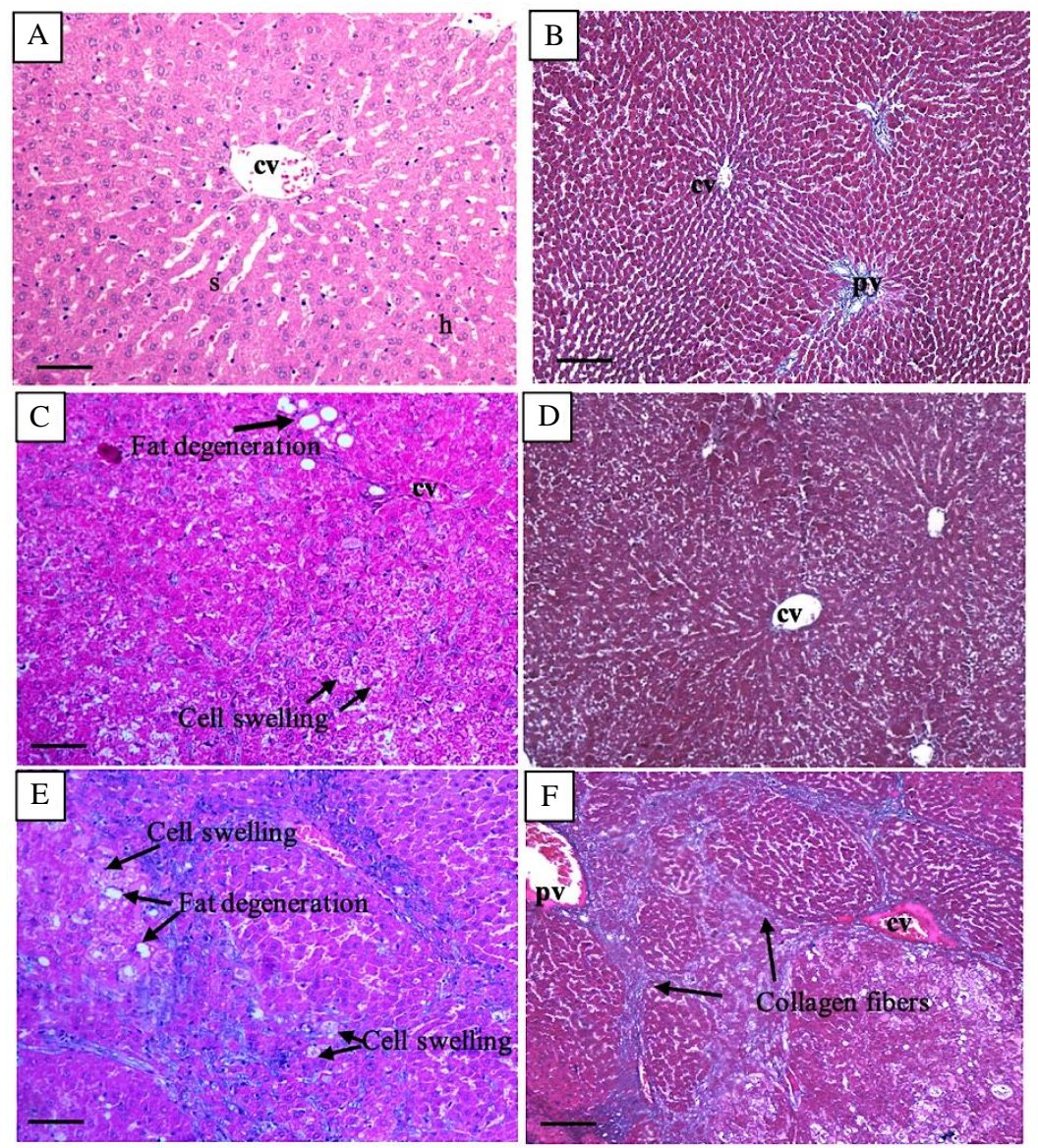

Fig. 2: Photomicrograph of liver stained with hematoxylin eosin (A,C,E) and Masson's trichome (B,D,F). A. Normal morphology of liver tissue (Group I) and B. Normal distribution of control collagen fibers (Group I). C, D. Group II. E, F. Group III. C and E show the morphology of liver damage. D shows distribution of collagen fibers in the perisinusoidal zone 3 or porta/periportal (score 2). F shows distribution of collagen fibers of cirrhosis tissue (score 4). Sinusoid (s), hepatocytes (h), central venous (cv), port (pv) with a bar scale of $10 \mu \mathrm{m}$ 

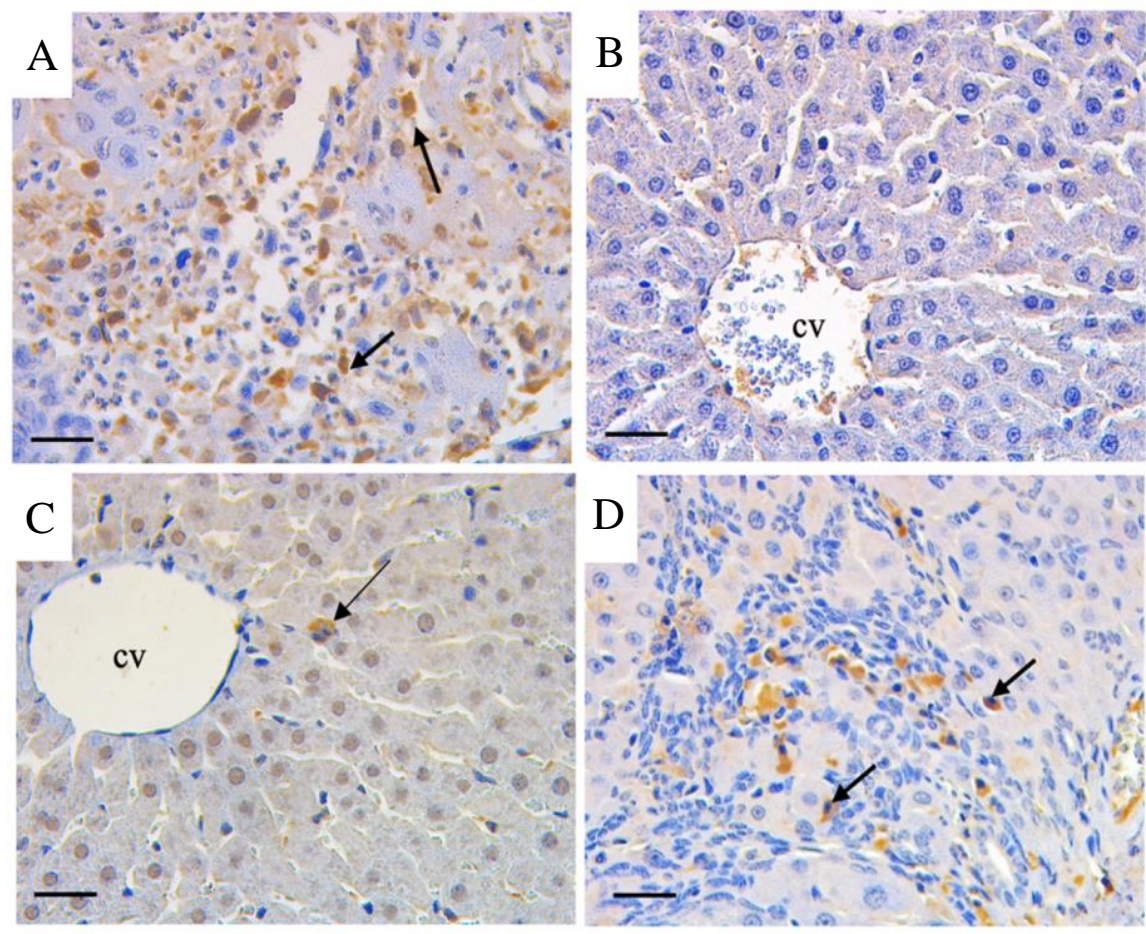

$\mathrm{E}$

Caspase-3 expression index

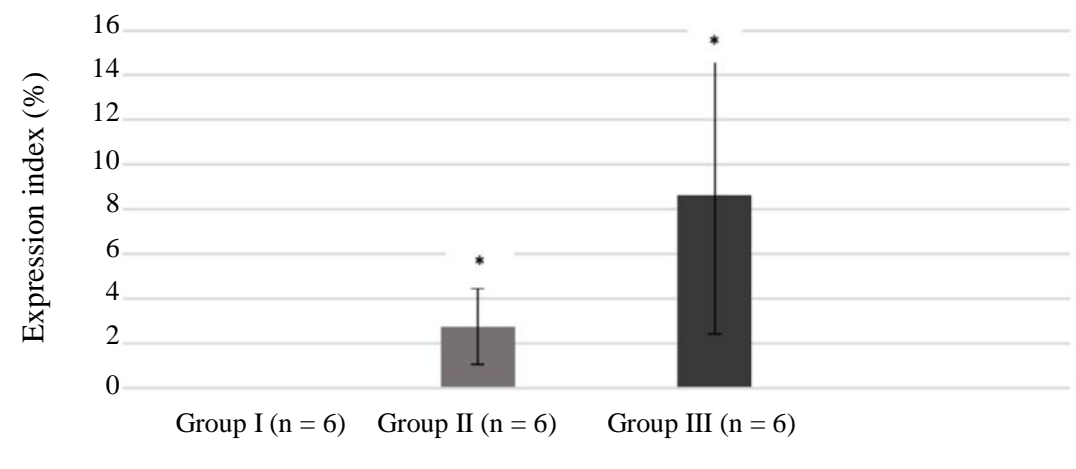

Fig. 3: Immunohistochemical staining of Caspase 3 in in rat liver tissue (400× magnification). A. Positive control tissue, human tonsils. Caspase 3 positive cells stained brown in their cytoplasm (arrow). B. Group I, liver tissue, showed no brown colored cytoplasm. C. Group II. D. Group III. E. Expression of Caspase 3 protein. Group $1=0$, Group II = 2,74\% and group III = $8.64 \%$. * Significant different of the expression index $(\mathrm{p}<0.05)$. Bar scale $=10 \mu \mathrm{m}$

Table 1: Liver damage score and degree of fibrosis

\begin{tabular}{llllll}
\hline Groups & Fat degeneration & Necrosis & Cell swelling & Inflammation & Degree of fibrosis \\
\hline I $(\mathrm{n}=6)$ & 0 & 0 & 0 & 0 & 0 \\
II $(\mathrm{n}=6)$ & $1(0-1)$ & 0 & $2(1-4)$ & $1(0-1)$ & $1(0-2)$ \\
III $(\mathrm{n}=6)$ & $1(0-1)$ & $1(0-1)$ & $2(0-4)$ & $1(0-1)$ & $1(1-4)$ \\
\hline
\end{tabular}

Note: Data is presented in Median (min-max)

Table 2: Coverage area (\%) of the liver damage and fibrosis

\begin{tabular}{lccccr}
\hline Groups & Fat degeneration & Necrosis & Cell swelling & Inflammation & Degree of fibrosis \\
\hline I $(\mathrm{n}=6)$ & 0 & 0 & 0 & 0 & 0 \\
II $(\mathrm{n}=6)$ & 30 & 0 & 100 & 17 & 87 \\
III $(\mathrm{n}=6)$ & 67 & 10 & 90 & 17 & 100 \\
\hline
\end{tabular}




\section{Conclusion}

Intravenous injection of single dose, $1 \times 10^{6} \mathrm{hUC}-\mathrm{MSC}$ could inhibit the progression of liver damage and reduce the liver fibrosis of $2 \mathrm{AAF} / \mathrm{CCl}_{4}$ rats. The treatment could decrease the apoptosis, shown by significant reduction of Caspase 3 expression. This treatment regimen has not significantly improved the liver function; nevertheless, a tendency of ALT decrease and Albumin increase was observed. Since the MSC was injected intravenously and the cells are mostly trapped in the lung, it may be necessary to increase the MSC doses for further studies.

\section{Acknowledgement}

We thank Firda Asma'ul Husna and Ayu Eka Fatril for fascilitating the manuscript preparation and continuation of the research. This research was supported by grant aid from Penelitian Dasar Unggulan Perguruan Tinggi (PDUPT) year 2020.

\section{Author's Contributions}

Isabella Kurnia Liem: Conception and design, funding acquisition, supervision, data interpretation, direct the content of the manuscript, final approval of the manuscript.

Reni Oktavina: Animal handling, histopatological staining, data acquisition, data analysis and interpretation, writing the manuscript.

Zakiyah: Animal handling, histopatological staining, data acquisition.

Dian Anggraini: Writing the proposal for research grant, stem cells preparation and injection, data analysis

Irwina Eka Deraya: Data analysis and writing the manuscript.

Ria Kodariah: Study design and metodology, data validation, analysis and interpretation, reviewing the manuscript.

Ening Krisnuhoni: Data validation, analysis and interpretation.

Puspita Eka Wuyung: Study desgin, data analysis and interpretation, review the manuscript.

\section{Ethics}

All animal experiments were approved by ethics committee of Faculty of Medicine Universitas Indonesia (No.1277/UN2.F1/ETIK/2018).

\section{References}

Abdellatif, H., Shiha, G., Saleh, D. M., Eltahry, H., \& Botros, K. G. (2017). Effect of human umbilical cord blood stem cell transplantation on oval cell response in 2-AAF/CCL4 liver injury model: experimental immunohistochemical study. Inflammation and Regeneration, 37(1), 1-8. https://doi.org/10.1186/s41232-017-0035-8
Best, J., Manka, P., Syn, W. K., Dollé, L., van Grunsven, L. A., \& Canbay, A. (2015). Role of liver progenitors in liver regeneration. Hepatobiliary Surgery and Nutrition, 4(1), 48. https://doi.org/10.3978/j.issn.2304-3881.2015.01.16

Burra, P., Arcidiacono, D., Bizzaro, D., Chioato, T., Di Liddo, R., Banerjee, A., ... \& Russo, F. P. (2012). Systemic administration of a novel human umbilical cord mesenchymal stem cells population accelerates the resolution of acute liver injury. BMC Gastroenterology, 12(1), 1-16. https://doi.org/10.1186/1471-230x-12-88

Cao, Y., Ji, C., \& Lu, L. (2020). Mesenchymal stem cell therapy for liver fibrosis/cirrhosis. Annals of Translational Medicine, 8(8). https://doi.org/10.21037/atm.2020.02.119

Cardinale, V., Carpino, G., Gentile, R., Napoletano, C., Rahimi, H., Franchitto, A., ... \& Alvaro, D. (2014). Transplantation of human fetal biliary tree stem/progenitor cells into two patients with advanced liver cirrhosis. BMC Gastroenterology, 14(1), 1-5. https://doi.org/10.1186/s12876-014-0204-z

Carvalho, A. B., Quintanilha, L. F., Dias, J. V., Paredes, B. D., Mannheimer, E. G., Carvalho, F. G., ... \& Goldenberg, R. C. (2008). Bone marrow multipotent mesenchymal stromal cells do not reduce fibrosis or improve function in a rat model of severe chronic liver injury. Stem Cells, 26(5), 1307-1314.

Crop, M. J., Korevaar, S. S., De Kuiper, R., Ijzermans, J. N., Van Besouw, N. M., Baan, C. C., ... \& Hoogduijn, M. J. (2011). Human mesenchymal stem cells are susceptible to lysis by CD8+ T cells and NK cells. Cell Transplantation, 20(10), 1547-1559. https://doi.org/10.3727/096368910X564076.

Eggenhofer, E., Benseler, V., Kroemer, A., Popp, F., Geissler, E., Schlitt, H., ... \& Hoogduijn, M. J. (2012). Mesenchymal stem cells are short-lived and do not migrate beyond the lungs after intravenous infusion. Frontiers in Immunology, 3, 297. https://doi.org/10.3389/fimmu.2012.00297

Eidi, A., Mortazavi, P., Behzadi, K., Rohani, A. H., \& Safi, S. (2013). Hepatoprotective effect of manganese chloride against $\mathrm{CCl}$ 4-induced liver injury in rats. Biological Trace Element Research, 155(2), 267-275. https://doi.org/10.1007/s12011-013-9784-7

Elmore, S. (2007). Apoptosis: a review of programmed cell death. Toxicologic Pathology, 35(4), 495-516. https://doi.org/10.1080/01926230701320337

Eom, Y. W., Kim, G., \& Baik, S. K. (2015). Mesenchymal stem cell therapy for cirrhosis: present and future perspectives. World Journal of Gastroenterology: WJG, 21(36), 10253. https://doi.org/10.3748/wjg.v21.i36.10253

Fazzina, R., Mariotti, A., Procoli, A., Fioravanti, D., Iudicone, P., Scambia, G., ... \& Bonanno, G. (2015). A new standardized clinical-grade protocol for banking human umbilical cord tissue cells. Transfusion, 55(12), 2864-2873. https://doi.org/10.1111/trf.13277 
GBD 2017 Cirrhosis Collaborators. (2020). The global, regional and national burden of cirrhosis by cause in 195 countries and territories, 1990-2017: a systematic analysis for the Global Burden of Disease Study 2017. Lancet Gastroenterol Hepatol, 5(3):245-66. https://doi.org/10.1016/S2468-1253(19)30349-8

Giannini, E. G., Testa, R., \& Savarino, V. (2005). Liver enzyme alteration: a guide for clinicians. Cmaj, 172(3), 367-379.

https://www.cmaj.ca/content/172/3/367.short

Habeeb, M. A., Vishwakarma, S. K., Bardia, A., \& Khan, A. A. (2015). Hepatic stem cells: A viable approach for the treatment of liver cirrhosis. World Journal of Stem Cells, 7(5), 859. https://doi.org/10.4252/wjsc.v7.i5.859

Haldar, D., Henderson, N. C., Hirschfield, G., \& Newsome, P. N. (2016). Mesenchymal stromal cells and liver fibrosis: a complicated relationship. The FASEB Journal, 30(12), 3905-3928. https://doi.org/10.1096/fj.201600433R

Hasan, S. K., \& Sultana, S. (2015). Geraniol attenuates 2acetylaminofluorene induced oxidative stress, inflammation and apoptosis in the liver of wistar rats. Toxicology Mechanisms and Methods, 25(7), 559-573. https://doi.org/10.3109/15376516.2015.1070225

$\mathrm{Hu}, \mathrm{C}$., \& Li, L. (2019). Improvement of mesenchymal stromal cells and their derivatives for treating acute liver failure. Journal of Molecular Medicine, 97(8), 1065-1084. https://doi.org/10.1007/s00109-019-01804-x

Hwang, S., Hong, H. N., Kim, H. S., Park, S. R., Won, Y. J., Choi, S. T., ... \& Lee, S. G. (2012). Hepatogenic differentiation of mesenchymal stem cells in a rat model of thioacetamide-induced liver cirrhosis. Cell Biology International, 36(3), 279-288. https://doi.org/10.1042/CBI20110325

Ishige, I., Nagamura-Inoue, T., Honda, M. J., Harnprasopwat, R., Kido, M., Sugimoto, M., ... \& Tojo, A. (2009). Comparison of mesenchymal stem cells derived from arterial, venous and Wharton's jelly explants of human umbilical cord. International Journal of Hematology, 90(2), 261-269. https://doi.org/10.1007/s12185-009-0377-3

Jiang, W., \& Xu, J. (2019). Immune modulation by mesenchymal stem cells. Cell Proliferation, 53(e12712), 1-16. https://doi.org/10.1111/cpr.12712

Lin, S. Y., Xu, D., Du, X. X., Ran, C. L., Xu, L., Ren, S. J., .. \& Shu, G. (2019). Protective effects of salidroside against carbon tetrachloride (CCl4)induced liver injury by initiating mitochondria to resist oxidative stress in mice. International Journal of Molecular Sciences, 20(13), 3187. https://doi.org/10.3390/ijms20133187
Lo, R. C., \& Kim, H. (2017). Histopathological evaluation of liver fibrosis and cirrhosis regression. Clinical and Molecular Hepatology, 23(4), 302. https://doi.org/10.3350/cmh.2017.0078

Mao, S. A., Glorioso, J. M., \& Rochester, S. L. (2014). Liver regeneration. Transl Research., 163(4), 352-362. https://doi.org/10.1016/j.trsl.2014.01.005

Marcellin, P., \& Kutala, B. K. (2018). Liver diseases: A major, neglected global public health problem requiring urgent actions and large-scale screening. Liver International, 38, 2-6. https://doi.org/10.1111/liv.13682

Maulidia, V. N. A. R., Wardhani, P., \& Setyoboedi, B. (2020). AST, ALT and Albumin Level in Chronic Hepatitis B Patients with and without Complications of Cirrhosis and Hepatocellular Carcinoma. Indonesian Journal of Clinical Pathology and Medical Laboratory, 26(3), 344-349.

https://indonesianjournalofclinicalpathology.org/ind ex.php/patologi/article/view/1588

Meier, R. P., Müller, Y. D., Morel, P., Gonelle-Gispert, C., \& Bühler, L. H. (2013). Transplantation of mesenchymal stem cells for the treatment of liver diseases, is there enough evidence?. Stem Cell Research, 11(3), 1348-1364.

https://doi.org/10.1016/j.scr.2013.08.011

Motawi, T. M., Atta, H. M., Sadik, N. A., \& Azzam, M. (2014). The therapeutic effects of bone marrowderived mesenchymal stem cells and simvastatin in a rat model of liver fibrosis. Cell Biochemistry and Biophysics, 68(1), 111-125. https://doi.org/10.1007/s12013-013-9698-1.

Nicolas, C., Wang, Y., \& Nyberg, S. L. (2016). Cell therapy in chronic liver disease. Current Opinion in Gastroenterology, 32(3), 189. https://doi.org/10.1097/MOG.0000000000000262.

Omara, E. A., El-Toumy, S. A., Shabana, M. E., Farrag, A. R. H., Nada, S. A., \& Shafee, N. (2018). The antifibrotic effect of Zilla spinosa extracts targeting apoptosis in CCl4-induced liver damage in rats. Journal of The Arab Society for Medical Research, 13(2), 129. https://doi.org/10.4103/jasmr.jasmr_29_18

Onyekwere, C. A., Ogbera, A. O., Samaila, A. A., Balogun, B. O., \& Abdulkareem, F. B. (2015). Nonalcoholic fatty liver disease: Synopsis of current developments. Nigerian Journal of Clinical Practice, 18(6), 703-712. https://doi.org/10.4103/1119-3077.163288

Riehle, K. J., Dan, Y. Y., Campbell, J. S., \& Fausto, N. (2011). New concepts in liver regeneration. Journal of Gastroenterology and Hepatology, 26, 203-212.

Shi, X. L., Gu, J. Y., Han, B., Xu, H. Y., Fang, L., \& Ding, Y. T. (2010). Magnetically labeled mesenchymal stem cells after autologous transplantation into acutely injured liver. World Journal of Gastroenterology: WJG, 16(29), 3674. https://doi.org/10.1111/j.1440-1746.2010.06539.x 
Thapaliya, S., Wree, A., Povero, D., Inzaugarat, M. E., Berk, M., Dixon, L., ... \& Feldstein, A. E. (2014). Caspase 3 inactivation protects against hepatic cell death and ameliorates fibrogenesis in a diet-induced NASH model. Digestive Diseases and Sciences, 59(6), 1197-1206.

https://doi.org/10.1007/s10620-014-3167-6

Troyer, D. L., \& Weiss, M. L. (2008). Concise review: Wharton's Jelly-derived cells are a primitive stromal cell population. Stem Cells, 26(3), 591-599. https://doi.org/10.1634/stemcells.2007-1028

Tsuchida, T., \& Friedman, S. L. (2017). Mechanisms of hepatic stellate cell activation. Nature Reviews Gastroenterology \&Hepatology, 14(7), 397. https://doi.org/10.1038/nrgastro.2017.38

Vangsness Jr, C. T., Sternberg, H., \& Harris, L. (2015). Umbilical cord tissue offers the greatest number of harvestable mesenchymal stem cells for research and clinical application: a literature review of different harvest sites. Arthroscopy: The Journal of Arthroscopic \& Related Surgery, 31(9), 1836-1843. https://doi.org/10.1016/j.arthro.2015.03.014

Volarevic, V., Nurkovic, J., Arsenijevic, N., \& Stojkovic, M. (2014). Concise review: therapeutic potential of mesenchymal stem cells for the treatment of acute liver failure and cirrhosis. Stem Cells, 32(11), 2818-2823. https://doi.org/10.1002/stem.1818
Xu, J., Liu, X., Koyama, Y., Wang, P., Lan, T., Kim, I. G., ... \& Kisseleva, T. (2014). The types of hepatic myofibroblasts contributing to liver fibrosis of different etiologies. Frontiers in Pharmacology, 5, 167. https://doi.org/10.3389/fphar.2014.00167

Yang, X., Meng, Y., Han, Z., Ye, F., Wei, L., \& Zong, C. (2020). Mesenchymal stem cell therapy for liver disease: full of chances and challenges. Cell \& Bioscience, 10(1), 1-18. https://doi.org/10.1186/s13578-020-00480-6

Yun, J. W., Ahn, J. H., Kwon, E., Kim, S. H., Kim, H., Jang, J. J., ... \& Kang, B. C. (2016). Human umbilical cord-derived mesenchymal stem cells in acute liver injury: Hepatoprotective efficacy, subchronic toxicity, tumorigenicity and biodistribution. Regulatory Toxicology and Pharmacology, 81, 437-447. https://doi.org/10.1016/j.yrtph.2016.09.029

Zhou, W. C., Zhang, Q. B., \& Qiao, L. (2014). Pathogenesis of liver cirrhosis. World journal of gastroenterology: WJG, 20(23), 7312. https://doi.org/10.3748/wjg.v20.i23.7312

Zhu, S., Rezvani, M., Harbell, J., Mattis, A. N., Wolfe, A. R., Benet, L. Z., ... \& Ding, S. (2014). Mouse liver repopulation with hepatocytes generated from human fibroblasts. Nature, 508(7494), 93-97. https://doi.org/10.1038/nature13020 